\title{
Reflets
}

Revue ontaroise d'intervention sociale et communautaire

\section{Le P'tit Bonheur : un programme du Patro d'Ottawa pour les personnes ayant un handicap intellectuel}

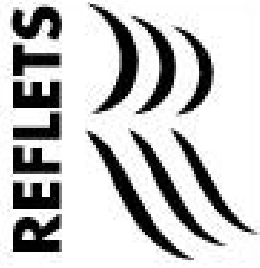

\section{Alain Poirier et Monique Morin-Lavigne}

Volume 4, numéro 2, automne 1998

Personnes vivant avec une incapacité

URI : https://id.erudit.org/iderudit/026238ar

DOI : https://doi.org/10.7202/026238ar

Aller au sommaire du numéro

Éditeur(s)

Reflets : Revue ontaroise d'intervention sociale et communautaire

ISSN

1203-4576 (imprimé)

1712-8498 (numérique)

Découvrir la revue

Citer ce document

Poirier, A. \& Morin-Lavigne, M. (1998). Le P’tit Bonheur : un programme du Patro d'Ottawa pour les personnes ayant un handicap intellectuel. Reflets, 4(2), 212-213. https://doi.org/10.7202/026238ar

Tous droits réservés $(\subset$ Reflets : Revue ontaroise d'intervention sociale et communautaire, 1998
Ce document est protégé par la loi sur le droit d'auteur. L'utilisation des services d’Érudit (y compris la reproduction) est assujettie à sa politique d'utilisation que vous pouvez consulter en ligne.

https://apropos.erudit.org/fr/usagers/politique-dutilisation/ 


\section{Le P'tit Bonheur: un programme du Patro d'Ottawa pour les personnes ayant un handicap intellectuel}

\section{Alain Poirier et Monique Morin-Lavigne}

Invariablement, à 11 heures 45, un mini-bus de Para-Transpo, le service responsable du transport des personnes ayant un handicap à Ottawa Carleton, s'immobilise devant le Patro d'Ottawa. Réglés comme une horloge, d'autres véhicules rouges et blancs font de même, déversant, chacun leur tour, les membres du P'tit Bonheur.

Marc, Jean-Pierre, Simone, Paulette et Éric débarquent du bus, précédés de leur chef naturel, Paulo. Bientôt, Gilles, Amanda, Marie-Thérèse, David, Josée et tous les autres se joindront à eux ${ }^{1}$.

Premier item à l'ordre du jour :le repas du midi où sandwichs, soupes, nouilles et lasagnes font bon ménage avec les salutations amicales, les taquineries d'usage et, parfois, la divulgation d'un p'tit malheur.

Les intervenantes et les intervenants profitent de cette période d'accueil pour pratiquer l'écoute active. On prend des nouvelles des bénéficiaires ou on assure un suivi à des questions restées en suspens (représentation, aiguillage, etc.).

Vient ensuite le moment d'orchestrer le déroulement de l'après-midi. Déjà les boîtes à lunch sont rangées. Un dernier café et le groupe se disperse dans les divers centres d'activités. 
Grâce à un partenariat avec La Magie des lettres, certaines personnes participent à des ateliers d'alphabétisation. Chacun évolue à son propre rythme, grâce à la présence de nombreux tuteurs et tutrices bénévoles. Les ateliers ont lieu deux fois la semaine et les progrès de chacun sont rigoureusement notés. Toutes et tous tirent profit de l'expérience: capacités accrues en lecture et en écriture, mais aussi une bonne mesure de confiance en soi.

À d'autres moments de la semaine, on proposera aux membres du groupe des ateliers d'habiletés de vie: hygiène personnelle, lire l'heure, compter son argent de poche et contrôler ses dépenses. Ici, le but de l'activité est aussi de permettre à chacune et à chacun d'atteindre son plein potentiel, tout en acquérant de nouvelles connaissances. C'est ainsi qu'en collaboration avec l'Association pour l'intégration sociale d'Ottawa Carleton, le Patro a pu offrir à ses membres un programme de cuisine collective.

Régulièrement, on propose également aux bénéficiaires des ateliers de croissance personnelle et des cercles de discussion où divers sujets sont abordés. Le printemps dernier, quatre sessions sur la prévention des abus sexuels, offerts par le Service familial catholique d'Ottawa Carleton, ont permis aux participantes et aux participants de se prémunir contre cette éventualité et d'exorciser des expériences douloureuses.

Des activités récréatives (jeux, bricolage, etc.) et sociales (danses, sorties de plein air, fêtes et banquets) viennent compléter le programme et font toujours la joie des participantes et des participants.

Déjà 16 heures, invariablement, voilà le chauffeur de ParaTranspo qui fait son apparition. Au revoir et à demain Paulo, Marc, Jean-Pierre, Simone, Paulette et tous les autres. Demain, nous finirons notre partie de cartes, juste avant de changer le monde, notre monde.

\section{Note}

1. Tous les noms utilisés dans ce texte sont fictifs. 